\title{
A SÍNTESE DA AMÔNIA: ALGUNS ASPECTOS HISTÓRICOS
}

\author{
Aécio Pereira Chagas \\ Instituto de Química, Universidade Estadual de Campinas, CP 6154, 13084-971 Campinas - SP, Brasil
}

Recebido em 16/5/05; aceito em 9/3/06; publicado na web em 26/9/06

\begin{abstract}
THE AMMONIA SYNTHESIS: SOME HISTORICAL ASPECTS. The ammonia synthesis from its elements plays an important role in the survival of humankind. A short historical development of discoveries of the nitrogen cycle, the nitrogen sources for agriculture and the ammonia synthesis (in laboratory and industry) are presented. Some brief aspects of nitrogen chemistry are described. Short biographies of Fritz Haber and Carl Bosch, the main persons in this epopee, are also presented.
\end{abstract}

Keywords: ammonia; Fritz Haber; Carl Bosch.

\section{A IMPORTÂNCIA DA SÍNTESE DA AMÔNIA}

Em 2 de julho de 1909, Fritz Haber (1868-1934) e seu assistente Robert Le Rossignol (1884-1976), em um laboratório da Universidade Técnica de Karlsruhe, demonstraram a Alwin Mittasch (18691953) e Julius Kranz, ambos da BASF (Badische Anilin und SodaFabrik), seu processo de produzir amônia a partir de hidrogênio e nitrogênio, utilizando ósmio como catalisador. A importância deste evento, seja do ponto de vista científico, técnico, social etc. é enorme. Ele pode ser mais bem aquilatado com o texto, com o qual Vaclav Smil inicia seu extraordinário livro Enriching the Earth ${ }^{1}$ : "Qual seria a mais importante invenção técnica do século XX? Aeroplanos, energia nuclear, vôo espacial, televisão e computadores estão entre as respostas mais comuns. Porém, nenhuma destas invenções teve a fundamental importância da sintese industrial da amônia a partir de seus elementos. $O$ viver das 6 bilhões de pessoas de nosso mundo poderia ser melhor sem o Microsoft Windows e a TV de 600 canais e nem os reatores nucleares ou ônibus espaciais são determinantes críticos do bem-estar humano. Mas a única e mais importante mudança afetando a população mundial - sua expansão de 1,6 bilhões de pessoas em 1900 para os atuais 6 bilhões - não teria sido possível sem a síntese da amônia."

A muitos é lamentável este aumento de população. Certamente este é um pensamento estreito e egoísta, pois todo progresso humano decorre de sermos mais: mais cabeças para pensar, mais braços para trabalhar, mais desafios a vencer, mais corações amando (e também odiando, não podemos esquecer) e muito mais. Entretanto, às vezes, as pessoas que detêm o poder desvirtuam, esquecendo que é preciso harmonia com o próximo.

Vamos, neste artigo, relatar de forma sucinta alguns episódios desta epopéia, tão importante, gloriosa e também uma parte do lado trágico a ela associada. Entretanto, para melhor compreendê-la é necessário traçar um breve histórico das descobertas que levaram ao conhecimento do ciclo do nitrogênio e sobre outras fontes desse elemento.

\section{O CICLO DO NITROGÊNIO}

Os estudos realizados com gases no século XVIII, geralmente denominados de Química Pneumática, levaram, independentemente, Joseph Priestley (1733-1804) e Jan Ingenhousz (1730-1799) a

*e-mail: aecio@mpcnet.com.br descreverem a fotosíntese das plantas verdes, retirando o "ar fixo" (o nosso dióxido de carbono) da atmosfera e produzindo "ar desflogisticado" (o nosso oxigênio) e o crescimento do vegetal. Os químicos franceses Louis Bernard G. de Morveau (1737-1816), Antoine L. Lavoisier (1743-1794), Claude-Louis Berthollet (17481822) e Antoine-François de Fourcroy (1755-1809) ao publicarem a nova nomenclatura química em 1787, denominaram o "ar mefítico" de azoto, que quer dizer "impróprio à vida". Já em 1790, Berthollet afirmava que todas as substâncias animais têm o elemento azoto e, neste mesmo ano, Jean Claude Chaptal (1756-1832) propunha o nome nitrogênio (gerador de nitro, o nosso nitrato de potássio), para este mesmo elemento. Em 1804, Nicholas T. Saussure (1767-1845) mostrou que as plantas não absorvem o nitrogênio atmosférico e todos os nutrientes são transportados pela água (inclusive o nitrogênio) e absorvidos pela raiz ${ }^{1-3}$.

Na primeira metade do séc. XIX, havia grande interesse em se estabelecer o balanço material da nutrição de plantas e animais e, neste trabalho, destacaram-se Jean-Baptiste Boussingault (18021887) e Justus Liebig (1803-1873). O primeiro começou sua carreira como professor de química em diversos locais; depois de se casar passou a admistrar a fazenda de seu sogro e lá realizou suas experiências. Determinou o teor de $\mathrm{N}$ em muitos materiais orgânicos (tecidos vegetais e animais, fezes, esterco etc.), procurando realizar o balanço material. Boussingault chamou a atenção de que o valor nutritivo de um fertilizante é proporcional ao seu teor de nitrogênio e que as leguminosas (feijões, ervilhas etc.) podem restaurar o nitrogênio do solo.

Liebig, o influente professor de Giessen (Alemanha), seguiu caminho semelhante e complementar - ele não tinha fazenda, mas seu laboratório era melhor - e começou a chamar a atenção sobre a importância dos nutrientes inorgânicos das plantas. Formulou as leis básicas da adubação, propôs o fertilizante inorgânico e divulgou suas idéias no livro de Química Orgânica. Foram as primeiras tentativas de se estabelecer o ciclo do nitrogênio ${ }^{1,4}$.

Em 1843, John B. Lawes (1814-1900), fazendeiro inglês, com a colaboração de Joseph H. Gilberr (1794-1878), discípulo inglês de Liebig, iniciaram experimentos de campo sobre fertilidade do solo, utilizando a análise química. O local, denominado Rothamste Experimental Station (Hertfordshire, Inglaterra) é até hoje utilizado com esta finalidade. Por volta de 1845 , surgem os primeiros fertilizantes inorgânicos comerciais na Inglaterra (misturas de cinzas vegetais, gesso, ossos calcinados, silicato de potássio e em alguns, sulfato de amônio) ${ }^{1}$. 
Entretanto, permaneciam ainda muitas incógnitas sobre o ciclo do nitrogênio. Como ele era "fixado" pelas plantas? O termo fixação tem sido usado para designar a transformação do nitrogênio atmosférico $\left(\mathrm{N}_{2}\right.$ gasoso) em compostos sólidos, líquidos ou em solução. Como Boussingault havia mostrado, e as práticas agrícolas já atestavam isto, o cultivo de leguminosas aumenta o teor de nitrogênio no solo, porém a planta não o absorve da atmosfera. Em 1885, Marcelin Berthelot (1827-1895) observa que o nitrogênio do ar pode ser absorvido e fixado, de uma forma desconhecida, em solo argiloso, não cultivado, em potes, mas não com o mesmo solo esterilizado. Nesta época a microbiologia já estava em pleno desenvolvimento. Entre 1886 e 1888, os alemães Hermann Hellriegel (1831-1895) e Hermann Wilfarth (1853-1904) relataram que as leguminosas fixavam o nitrogênio atmosférico por meio de microrganismos presentes nos nódulos de suas raízes, porém as gramíneas (trigo, arroz, milho, sorgo etc.) não. Estes nódulos eram descritos na literatura desde pelo menos o séc. XVII. Em 1889, Martinus Beijerinck (1851-1931), microbiologista holandês, isolou uma bactéria Rhizobium dos nódulos das raízes e, logo depois, Albert Frank (1839-1900) relatou a fixação do nitrogênio em cianobactérias, na época conhecidas por algas verde-azuladas ${ }^{1}$.

Paralelamente a estas descobertas, havia grande atividade de microbiologistas que foram elucidando as transformações das diferentes espécies de nitrogênio no solo $\left(\mathrm{NO}_{3}^{-}(\mathrm{aq}), \mathrm{NO}_{2}^{-}(\mathrm{aq}), \mathrm{NH}_{4}^{+}(\mathrm{aq})\right.$, $\mathrm{NH}_{3}(\mathrm{aq})$ e $\mathrm{N}_{2}(\mathrm{~g})$ ), realizadas por microrganismos, destacando-se o biólogo russo Sergei N. Winogradsky (1856-1953). Várias outras espécies fixadoras de nitrogênio foram encontradas, inclusive em outras plantas e, finalmente, pôde-se elucidar o ciclo do nitrogênio na natureza (Figura 1). O nitrogênio é um elemento presente nas principais moléculas de importância biológica (proteínas, RNA, DNA etc.) e mostrou-se fundamental para a proliferação dos seres vivos, a qual, por sua vez, está condicionada pela abundância dos elementos disponíveis. O nitrogênio, mais do que qualquer outro, é o gargalo devido à sua inércia química ${ }^{1,5,6}$.

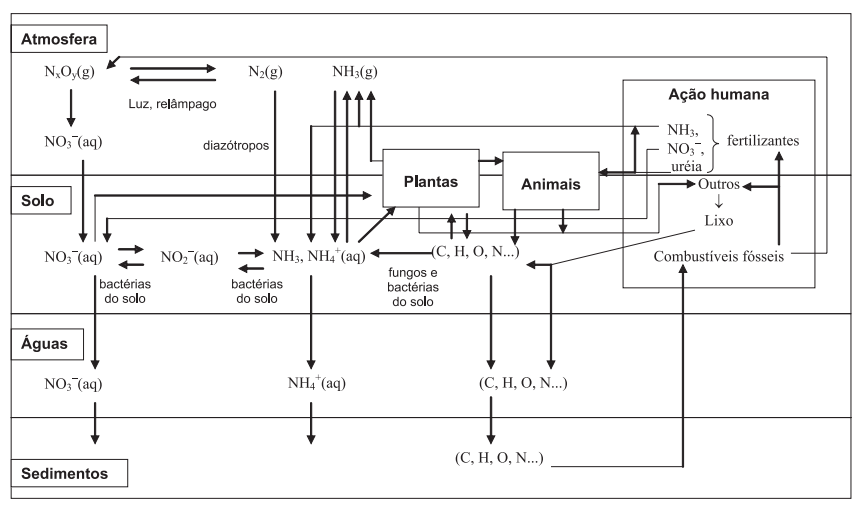

Figura 1. Parte do ciclo do nitrogênio destacando-se as atividades agrícolas. $(C, H, O, N \ldots)=$ matéria orgânica. Adaptado das refs. 1 e 5

\section{UM POUCO DA QUÍMICA DO NITROGÊNIO}

O nitrogênio, elemento de número atômico 7 e massa molar relativa 14,007 , é o principal componente de nossa atmosfera $(78,0 \%)$, porém encontra-se em quantidades menores na litosfera e na hidrosfera. A Figura 2 resume alguns aspectos da química do nitrogênio, levando em consideração apenas as espécies de interesse natural, inclusive a glicina, o mais simples aminoácido, representando toda a classe. Na abscissa está representado o número de oxidação (nox) do nitrogênio e na ordenada, a energia livre de formação da espécie química, $\Delta \mathrm{f} G^{\theta}$, (à pressão padrão $p^{\theta}=0,1 \mathrm{MPa}$ e temperatura
$T=298,15 \mathrm{~K}$ ), em relação aos elementos em sua forma alotrópica mais estável. Nos pontos de valor nulo passam duas retas tracejadas que se cruzaram no dinitrogênio, $\mathrm{N}_{2}(\mathrm{~g}),\left(\right.$ nox $=0$ e $\left.\Delta \mathrm{f} G^{\theta}=0 \mathrm{~kJ} / \mathrm{mol}\right)$, dividindo o plano em quatro partes. No quadrante superior direito estão os óxidos de nitrogênio $\left(\mathrm{N}_{\mathrm{x}} \mathrm{O}_{\mathrm{y}}\right)$, todos com nox $>0$ e $\Delta \mathrm{f} G^{\theta}>0$. O valor desta última grandeza indica que todos os óxidos são menos estáveis, termodinâmicamente, que seus elementos formadores $\left(\mathrm{N}_{2}(\mathrm{~g})\right.$ e $\mathrm{O}_{2}(\mathrm{~g})$ ), nas condições indicadas. No quadrante direito inferior estão os ânions nitrato, $\mathrm{NO}_{3}^{-}(\mathrm{aq})$ e nitrito, $\mathrm{NO}_{2}^{-}(\mathrm{aq})$, ambos em solução aquosa diluida e apresentam $\Delta \mathrm{f} G^{\theta}<0$, ou seja, são mais estáveis que seus elementos formadores. No quadrante inferior esquerdo estão as formas reduzidas do $\mathrm{N}$, nox $<0$, toda elas mais estáveis que os elementos formadores. Apesar de pouca estabilidade termodinâmica, os óxidos de nitrogênio são encontrados na atmosfera por razões cinéticas. Os ânions, em meio aquoso, são mais estáveis, porém são facilmente assimilados e metabolizados por seres vivos (bactérias ou plantas). Assim também as espécies reduzidas, inclusive o $\mathrm{NH}_{3}(\mathrm{~g})$ que facilmente se dissolvem na água ${ }^{7}$. A espécie mais abundante é sem dúvida o $\mathrm{N}_{2}(\mathrm{~g})$, justamente pela sua inércia química. A molécula do dinitrogênio apresenta uma tripla ligação muito forte. Para sua cisão são necessários 945,4 kJ/mol nas condições ambientes ${ }^{8}$. Reações do dinitrogênio vão requerer entalpias de ativação desta ordem de grandeza, ou seja, valores de energia elevados para romper a tripla ligação, daí a dificuldade de se transformar esta espécie nas outras. Apesar de sua abundância na atmosfera, a inércia química do $\mathrm{N}_{2}(\mathrm{~g})$ faz com que os nutrientes com esse elemento acabem sendo o gargalo mencionado acima.

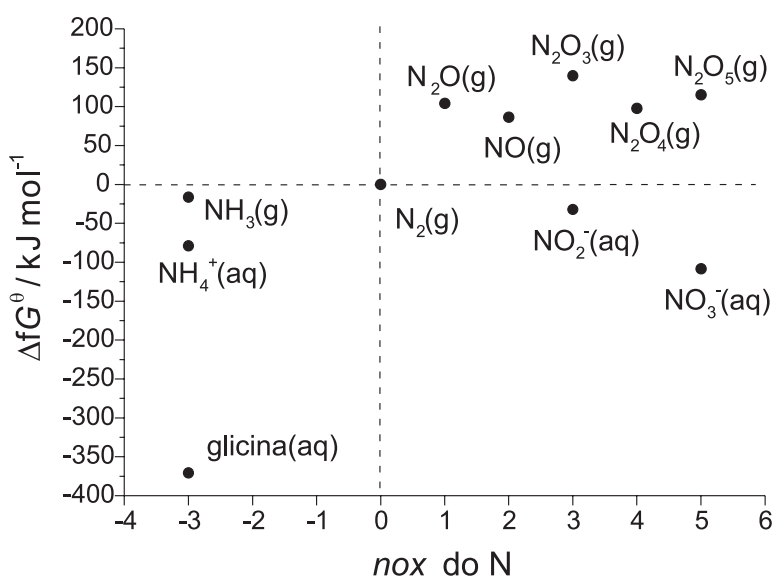

Figura 2. Energia livre padrão de formação $\left(\Delta f \mathrm{G}^{\theta} / \mathrm{kJ} \mathrm{mol}^{-1}\right)$ de espécies nitrogenadas de interesse natural em função do número de oxidação (nox) desse elemento. Utilizando-se os dados da ref. 9

A formação da amônia a partir dos elementos, assim representada:

$1 / 2 \mathrm{~N}_{2}(\mathrm{~g})+3 / 2 \mathrm{H}_{2}(\mathrm{~g})=\mathrm{NH}_{3}(\mathrm{~g})$

é uma reação exotérmica, ou seja, $\Delta \mathrm{f} H^{\theta}=-45,898 \mathrm{~kJ} / \mathrm{mol}$ a 298,15 $\mathrm{K}$ e, nesta mesma temperatura é termodinamicamente favorecida: $\Delta \mathrm{f} G^{\theta}=-16,367 \mathrm{~kJ} / \mathrm{mol}^{9}$. A Figura 3 apresenta um diagrama de Ellingham ${ }^{10}\left(\Delta \mathrm{f} G^{\theta}(p)=\mathrm{f}(T)\right)$ para este sistema à pressão padrão $\left(p^{\theta}=0,1 \mathrm{MPa}\right)$ e às pressões de 1,10 e $30 \mathrm{MPa}$, considerando o sistema ideal ${ }^{9}$. Nota-se que à pressão padrão $\Delta \mathrm{f} G^{\theta}=0 \mathrm{~kJ} / \mathrm{mol}$ (constante de equilíbrio de formação $K \mathrm{f}=1$ ) a cerca de $450 \mathrm{~K}$; acima desta temperatura o equilíbrio estará deslocado para a esquerda (para o lados dos elementos) e abaixo, o equilíbrio seria favorável à formação da amônia. Com o aumento da pressão, o equilíbrio se desloca para a direita, no sentido da contração do volume (Princípio de 
Le Chatelier, $\Delta \mathrm{f} V^{\theta}=-V^{\theta}(\mathrm{g}$, ideal $\left.)=\mathrm{R} T / \mathrm{p}^{\theta}\right)$. A $600 \mathrm{~K}$ a reação é desfavorável à pressão padrão $\left(\Delta \mathrm{f} G^{\theta}>0\right)$, porém favorável a $p=10$ e $30 \mathrm{MPa}(\Delta \mathrm{f} G<0)$. Como será descrito abaixo, a epopéia da síntese da amônia começou com o estabelecer destas propriedades termodinâmicas em um sistema tremendamente inerte.

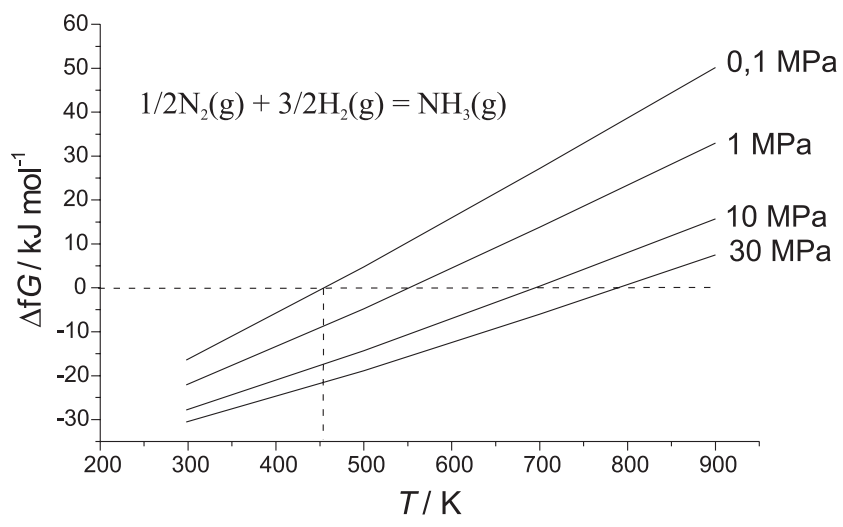

Figura 3. Diagrama de Ellingham, $\Delta f \mathrm{G}=f(\mathrm{~T})$, para a formação da amônia, a partir dos elementos, a diversas pressões. Utilizou-se os dados da ref. 9

\section{FONTES DE NITROGÊNIO PARA A AGRICULTURA}

Até o final do século XVIII, a agricultura utilizava fontes de nitrogênio provenientes do próprio local: restos de colheita, excrementos animais e humanos etc., modificados (compostagem) ou não. A rotação das colheitas, uma ou duas colheitas de gramíneas e depois uma de leguminosa, era outro recurso utilizado; outro método era deixar a terra "descansando" um certo tempo (os microorganismos do solo recuperavam o teor de nitrogênio). Talvez o melhor exemplo desta agricultura, hoje chamada "orgânica", fosse a praticada nas planícies da China, onde tudo era aproveitado e sua alta produtividade conseguia manter a elevada população deste país. A fome, vez por outra, conforme o regime de chuvas ou alguma outra circunstância, castigava a população ${ }^{1}$.

$\mathrm{Na}$ Europa, nesta época, com os acima citados trabalhos dos químicos, começou-se a procura por outras fontes de nitrogênio, longe dos campos agrícolas. Uma das primeiras fontes foi o guano. No Oceano Pacífico, nas costas do Peru, em certo período do ano, há uma grande concentração de peixes e as aves marítimas vão ali se alimentar e acasalar, nidificando nas ilhas da costa, longe dos homens. Durante séculos e séculos assim fizeram e seus excrementos foram se acumulando, chegando em alguns locais a ter uma expessura de $30 \mathrm{~m}$. A descoberta desdes depósitos e de seu valor como fertilizante, no início do século XIX, levou os europeus e norte-americanos a importarem este material de forma intensa, que rapidamente se esgotou. Outra fonte de nitrogênio, explorada a partir de 1830, foram os depósitos de salitre do Chile $\left(\mathrm{NaNO}_{3}\right)$, existentes nos desertos chilenos, na cordilheira dos Andes. Antigos lagos salgados evaporaram, deixando estes depósitos de sais misturados com argilas (caliche), que eram extraídos do solo, moídos, lavados e a solução obtida posta a evaporar, cristalizando o nitrato de sódio ${ }^{1}$.

A partir da década de 1870, surge, na Europa, outra fonte de nitrogênio, já indústrial: as chamadas "águas amoniacais" obtidas durante a destilação seca da hulha (carvão mineral) para obtenção do coque. Dos produtos voláteis obtidos durante o aquecimento, uma fração volátil contendo amônia é recebida em ácido sulfúrico e a solução resultante é evaporada, cristalizando o sulfato de amônio utilizado como fertilizante. Apesar de ser até hoje utilizado, a quantidade produzida deste sal é insuficiente e isto já desde o século $\mathrm{XIX}^{1,11}$.
Em setembro de 1898, em Bristol (Inglaterra), no seu discurso presidencial da reunião da Associação Britânica para o Progresso da Ciência, denominado O Problema do Trigo, William Crookes (1832-1919) chama a atenção para diversos e importantes itens: a deficiente produção de trigo na Inglaterra e em outras partes do mundo, a necessidade de mais nitrogênio, a limitação e o esgotamento do salitre do Chile, a enorme disponibilidade de nitrogênio na atmosfera e a necessidade de se encontrar uma maneira de fixálo, afirmando que isto seria feito em um futuro próximo. Concluía: "É o químico que deve vir salvar-nos... É por meio do laboratório que a fome poderá ser transformada em plenitude." Em vista do prestígio científico que Crookes gozava e da realidade da situação, que era bem conhecida nos meios econômicos de então, seu discurso teve grande repercussão e, de certo modo, provocou uma "corrida do nitrogênio" nos laboratórios ${ }^{1,11}$.

Para "fixação do nitrogênio", ou seja, para transformar o nitrogênio gasoso em algum composto sólido ou líquido, havia várias possibilidades, que podem ser percebidas na Figura 2. $\mathrm{O} \mathrm{N}_{2}(\mathrm{~g})$ pode ser oxidado aos óxidos, pode ser oxidado aos ânions ou pode ser reduzido a outros compostos, inclusive amônia. A conversão aos óxidos é termodinâmicamente desfavorável, porém a altas temperaturas a formação dos mesmos passa a ser factível. As outras duas possibilidades já são favorecidas termodinamicamente, porém em todos os casos há a barreira cinética da inércia do $\mathrm{N}_{2}(\mathrm{~g})$.

Uma alternativa que começou a ser comercializada em 1901 foi a da cianamida cálcica. $\mathrm{O}$ carbeto de cálcio, $\mathrm{CaC}_{2}(\mathrm{~s})$, produto já conhecido para produção de acetileno e vulgarmente conhecido entre nós por carbureto, ao ser aquecido em presença de $\mathrm{N}_{2}(\mathrm{~g})$ puro a $1000{ }^{\circ} \mathrm{C}$ produz a cianamida cálcica, $\mathrm{CaCN}_{2}(\mathrm{~s})$, que é hidrolisada, produzindo carbonato de cálcio e amônia. As reações podem ser assim representadas:

$$
\begin{aligned}
& \mathrm{CaO}(\mathrm{s})+3 \mathrm{C}(\mathrm{s})=\mathrm{CaC}_{2}(\mathrm{~s})+\mathrm{CO}(\mathrm{g}) ;>1000{ }^{\circ} \mathrm{C} \text { (forno elétrico) (2) } \\
& \mathrm{CaC}_{2}(\mathrm{~s})+\mathrm{N}_{2}(\mathrm{~g})=\mathrm{CaCN}_{2}(\mathrm{~s})+\mathrm{C}(\mathrm{s}) ; \sim 1000{ }^{\circ} \mathrm{C} \\
& \mathrm{CaCN}_{2}(\mathrm{~s})+3 \mathrm{H}_{2} \mathrm{O}(\mathrm{l})=\mathrm{CaCO}_{3}(\mathrm{~s})+2 \mathrm{NH}_{3}(\mathrm{~g})(\text { no solo) }
\end{aligned}
$$

A rota da cianamida parecia ser interessante, pois o produto comercializado era um sólido, a cianamida, e no solo produzia a desejada amônia, que era oxidada pelos microrganismos a nitrato, espécie preferida pelas plantas, e carbonato de cálcio, que repunha cálcio ao solo, nutriente essencial, e corrigia a acidez. Entretanto era altamente consumidora de energia elétrica. As instalações indústriais européias ficavam geralmente próximas aos Alpes, aproveitando as quedas d'águas da região para produzirem eletricidade ${ }^{1,11}$.

A obtenção dos óxidos de nitrogênio a alta temperatura foi também bastante estudada. A temperatura do arco elétrico $\left(>2.000{ }^{\circ} \mathrm{C}\right)$ formam-se pequenas quantidades de NO (cerca de $0,34 \%$ no equilíbrio) e outros óxidos, os quais, rapidamente resfriados, são depois transformados em $\mathrm{NO}_{2}$ e absorvidos em água, formando ácido nítrico. Este processo do arco elétrico ficou conhecido pelo nome de Birkeland-Eyde. Suas reações podem ser assim representadas ${ }^{1,11,20}$ :

$$
\begin{aligned}
& \mathrm{N}_{2}(\mathrm{~g})+\mathrm{O}_{2}(\mathrm{~g})=2 \mathrm{NO}(\mathrm{g}) ; \sim 3.000{ }^{\circ} \mathrm{C} \\
& 2 \mathrm{NO}(\mathrm{g})+\mathrm{O}_{2}(\mathrm{~g})=2 \mathrm{NO}_{2}(\mathrm{~g}) ;<600{ }^{\circ} \mathrm{C} \\
& 2 \mathrm{NO}_{2}(\mathrm{~g})+\mathrm{H}_{2} \mathrm{O}(\mathrm{l})=\mathrm{HNO}_{3}(\mathrm{aq})+\mathrm{HNO}_{2}(\mathrm{aq}) \\
& 3 \mathrm{HNO}_{2}(\mathrm{aq})=\mathrm{HNO}_{3}(\mathrm{aq})+2 \mathrm{NO}(\mathrm{g})+\mathrm{H}_{2} \mathrm{O}(\mathrm{l}) \\
& 2 \mathrm{HNO}_{3}(\mathrm{aq})+\mathrm{CaO}(\mathrm{s})=\mathrm{Ca}\left(\mathrm{NO}_{3}\right)_{2}(\mathrm{aq})+\mathrm{H}_{2} \mathrm{O}(\mathrm{l})
\end{aligned}
$$




\section{HISTÓRICO DA SÍNTESE DA AMÔNIA}

Muitas foram as tentativas de se sintetizar a amônia já no século XIX. Estes fracassos acabavam por mostrar uma impossibilidade de se conseguir a reação. Entretanto, com o desenvolvimento da Termodinâmica e da Cinética, principalmente os estudos de catálise, aumentavam também as esperanças. Talvez seja mais interessante começar a história em 1884 com o estudo cinético de William Ramsay (1852-1916) e Sidney Young (1857-1937) da decomposição da amônia sobre um filamento de ferro aquecido a $800{ }^{\circ} \mathrm{C}$, produzindo $\mathrm{H}_{2}$ e $\mathrm{N}_{2}$. Observaram que no final restavam traços de $\mathrm{NH}_{3}$, porém não se observava nada quando se partia da mistura de hidrogênio e nitrogênio, nas mesmas condições e não conseguiram dar explicação ao ocorrido. Em 1898 houve o já mencionado discurso de Crookes, provocando a "corrida do nitrogênio"1,11.

Na Universidade de Leipzig (Alemanha), em 1900, Wilhelm Ostwald (1853-1932) afirmou ter obtido amônia a partir de hidrogênio e nitrogênio em presença de ferro. Notificou as empresas BASF e Hoechst e, ao mesmo tempo, requereu uma patente, onde já havia os pontos fundamentais da futura síntese: alta temperatura, alta pressão, catalisador metálico e circulação dos gases. Heinrich von Brunck (1847-1911), diretor da BASF designou um jovem químico, Carl Bosch (1874-1940), para testar a afirmação de Ostwald. Em seu relatório (1900), Bosch afirmou que a pequena quantidade de amônia obtida por Ostwald não era devida à sintese, mas à hidrogenação do nitreto de ferro $\left(\mathrm{Fe}_{3} \mathrm{~N}\right)$, formado durante a preparação do catalisador. Ostwald, muito a contragosto, retirou seu pedido de patente $\mathrm{e}^{1,12}$.

Em 1901, em Paris, Henry Louis Le Chatelier (1850-1936) começou também a trabalhar com a síntese. Ele havia calculado em 1900 a temperatura, a pressão e a quantidade de catalisador de ferro para a síntese, utilizando seus conhecimentos de Termodinâmica. Em 1901, seu aparelho de alta pressão explodiu, matando um dos ajudantes do laboratório e Le Chatelier desistiu dos experimentos ${ }^{1,11}$.

A empresa vienense Österreichische Chemische Werke, dirigida pelos irmãos R. e O. Margulies, em 1904 procurou Haber, ainda Privatdozent (título equivalente à nossa Livre-docência) em Karlsruhe para uma orientação e quiçá um desenvolvimento posterior sobre a fixação do nitrogênio. Inicialmente, Haber indicou Ostwald (Haber desconhecia o que houvera em 1900, inclusive o pedido de patente), porém parece que ele não se interessou. Haber então, com seu assistente Gabriel van Oordt, partindo dos resultados de Ramsay e Young, realizou o seguinte experimento: passou uma corrente muito lenta de amônia sobre pó de ferro aquecido a $1000{ }^{\circ} \mathrm{C}$ e separou a amônia não decomposta; passou, a seguir, os gases obtidos na decomposição (nitrogênio e hidrogênio) sobre o mesmo catalisador e obteve uma quantidade de amônia muito próxima da não decomposta. Isto significou que ele atingiu o estado de equilíbrio partindo das "duas pontas", ou seja, pela decomposição e pela síntese,

$$
1 / 2 \mathrm{~N}_{2}(\mathrm{~g})+3 / 2 \mathrm{H}_{2}(\mathrm{~g}) \underset{\text { decomposição }}{\stackrel{\text { síntese }}{\rightleftarrows}} \mathrm{NH}_{3}(\mathrm{~g})
$$

e verificou que o valor da constante de equilíbrio era muito baixo, pois a amônia obtida estava entre 0,005 a $0,0125 \%$, à pressão ambiente. Obteve praticamente os mesmos resultados com níquel, cálcio e manganês, como catalisadores. Percebeu também que o rendimento aumentara com o decréscimo da temperatura e a relação ótima de nitrogênio e hidrogênio era a estequiométrica (1:3). Haber achou que a reação não era recomendável. A empresa de Viena pagou generosamente por este resultado negativo ${ }^{1,11-13}$.

Em 1906, Hermann Walter Nernst (1864-1941) publicou seu Teorema do Calor, hoje conhecido como $3^{\mathrm{a}}$ Lei da Termodinâmica, pelo qual recebeu o Prêmio Nobel de Física de 1920. Com este teorema era possível calcular constantes de equilíbrio (e, portanto, rendimentos) de sistemas em fase gasosa utilizando dados térmicos das substâncias puras envolvidas na reação. Neste mesmo ano, ao revisar dados de equilíbrio, Nernst observou que os dados publicados de Haber e van Oordt afastavam-se de suas previsões teóricas e confiou a seu assistente Fritz Jost a tarefa de replicar o experimento sobre o sistema $\left(\mathrm{H}_{2}, \mathrm{~N}_{2}, \mathrm{NH}_{3}\right)$. Ele utilizou outras técnicas (autoclave) e ampliou as faixas de temperatura e pressão. Dentre os valores encontrados: a $1000{ }^{\circ} \mathrm{C}(1273 \mathrm{~K})$ e 1 atm $(0,1 \mathrm{MPa}), 0,0032 \%$ de amônia no equilíbrio (Haber encontrara $0,0125 \%$ ). O valor teórico de Nernst era $0,0045 \%$. Nernst escreveu a Haber e este com seu assistente Robert Le Rossignol repetiu o experimento de 1904 e encontraram, nas mesmas condições, $0,0048 \%$, uma boa confirmação do teorema de Nernst, porém longe de seus dados experimentais. A rigor, Nernst e Jost foram os primeiros a sintetizarem a amônia sob pressão de $50 \mathrm{~atm}(5 \mathrm{MPa})^{1,11-13}$.

Enquanto isto Haber e seu outro assistente A. Köning (18561901) trabalharam também no processo de formação do NO pelo arco elétrico, estabelecendo um contrato com a BASF, tanto para este processo como para a eventual síntese da amônia a partir de nitrogênio e hidrogênio. Variando condições conseguiram melhorar os resultados, aumentando o rendimento de 10 a $15 \%$ de NO, em relação ao procedimento usual. Neste ano a BASF, associada à Norsk Hydro, proprietária do processo do arco Birkeland-Eyde, iniciou a operação de uma fábrica em Kristianssand, no sul da Noruega ${ }^{1,11-13}$.

Haber publicou seus dados experimentais, obtidos com Le Rossignol, que vem a lume uma semana antes do encontro anual da Sociedade Bunsen (sociedade alemã de Físico-química), em maio de 1907. Nesta reunião Nernst ridicularizou publicamente Haber, considerando seus dados como errôneos! Haber, que já havia desistido de trabalhar com a síntese da amônia devido aos baixos rendimentos, estava agora determinado a se desforrar de Nernst. Com Le Rossignol realizou novos experimentos, agora a 30 atm (3,0 MPa). Novamente os mesmos resultados anteriores e notaram as vantagens e as possibilidades da alta pressão: a $500{ }^{\circ} \mathrm{C}(773 \mathrm{~K})$ e $30 \mathrm{~atm}$ $(3,0 \mathrm{MPa})$ a fração de amônia é 28 vezes maior que à pressão ambiente $(0,1 \mathrm{MPa})$. Isto entusiasmou Haber, pois novos cálculos mostravam que a 200 atm (20 MPa) (a pressão limite na época no laboratório) e $600{ }^{\circ} \mathrm{C}(873 \mathrm{~K})$ haveria $8 \%$ de amônia em equilíbrio e, ao mesmo tempo, ele se convenceu que o processo do arco elétrico não teria sucesso, inclusive pela dificuldade de ampliar a escala. Neste ínterim, Haber familiarizou-se com o novo processo de liquefação do ar e com a formação de formiato, partindo-se de hidróxido de sódio e monóxido de carbono sob pressão $0^{1,11-13}$.

É interessante notar que existem dois problemas conjuntos: a determinação da constante de equilíbrio da formação da amônia e seu processo de obtenção por este caminho. Praticamente Nernst e Haber resolveram o primeiro, porém restava o segundo.

Em 1908, Haber e Le Rossignol deram o "grande salto": projetaram, construíram, modificaram, até que funcionasse, um novo aparelho em que a mistura gasosa de nitrogênio e hidrogênio a $200 \mathrm{~atm}$ (20 MPa), introduzida em um reator, onde era pre-aquecida com o calor da reação que ocorre no leito catalítico e, após aí passar, ia a um separador onde a amônia era liquefeita e separada; os gases que não reagiram recircularam para o reator. A Figura 4 mostra um esquema do aparelho. A peça principal, o reator, era um tubo vertical, de $75 \mathrm{~cm}$ de comprimento e 13 de diâmetro ${ }^{25}$. Haber e Le Rossignol utilizaram outros catalisadores de maior eficiência: ósmio e urânio. Neste mesmo ano Haber solicitou uma patente para este aparelho e outra para o catalisador de ósmio ${ }^{1,11-13}$.

Em 3/7/1909 vão ao laboratório de Karlsruhe três representantes da BASF, a fim de conhecerem o processo de laboratório, Carl 


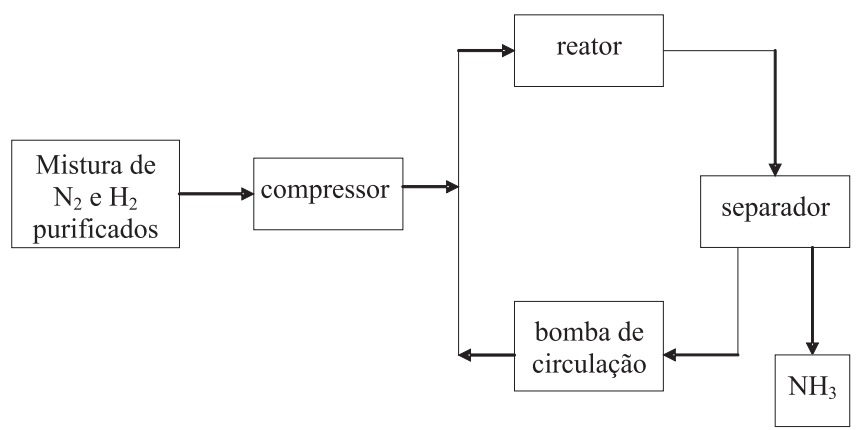

Figura 4. Esquema do aparelho de Haber e Le Roussignol para síntese da amônia a 200 atm (20 MPa) a partir de nitrogênio e hidrogênio na proporção de $1: 3$, respectivamente

Bosch, Alwin Mittasch e Julius Kranz. Chegam pela manhã e, como sói acontecer nestas ocasiões, o aparelho não funciona, porém pela tarde (Bosch já havia retornado a Ludwigshafen, sede da BASF), eles vêem a máquina funcionar produzindo 2 a $2,5 \mathrm{~cm}^{3}$ de $\mathrm{NH}_{3}(1)$ por min. Segundo os presentes foram momentos dramáticos e após ver a amônia gotejando, Mittasch cumprimentou Haber. Em setembro, Haber requer a patente para produção de amônia a pressões maiores que $100 \mathrm{~atm}(10 \mathrm{MPa})^{1,11-13}$.

Conta-se que, neste entretempo, Nernst também procurava construir um aparelho de alta pressão para sintetizar a amônia. Procurou um "expert" da indústria e perguntou se seria possível construir um aparelho que pudesse funcionar a várias centenas de atmosferas e à temperatura do ferro em brasa. A resposta foi negativa e Nernst acabou desistindo. Haber, pelo contrário, era um autodidata e não procurou nenhum especialista. Ele e seu pupilo Le Rossignol, que também era um hábil mecânico, puseram-se a trabalhar ${ }^{12,13}$.

Logo após Mittasch relatar à sua empresa os resultados de Haber, começaram, sob a supervisão de Bosch, os estudos para fabricar amônia pela síntese: ampliar a escala, procurar catalisadores mais baratos e, quiçá, mais eficientes e projetar uma fábrica ${ }^{1}$.

Após o pedido de patente e a assinatura do contrato de Haber com a BASF, várias outras companhias (Kunheim, GriesheimElektron, Hoechst) e Fritz Jost, colaborador de Nernst, que em 1906 havia obtido a amônia a 50 atm $(5,0 \mathrm{MPa})$, contestaram a patente básica de Haber. No dizer de Smil, a BASF astuciosamente manipulou seu principal oponente: Walter Nernst (aliado com Griesheim), oferecendo-lhe um "honorário" anual de 10.000 marcos por 5 anos e ele prontamente empenhou-se "como um dever nacional" em defender a patente de Haber. A Hoechst recrutou Ostwald para sua causa. Os rivais Haber e Nernst ficaram lado a lado no tribunal. Haber-BASF venceram a disputa em 4/3/1912. Neste dia, ainda no dizer de Smil, na sala do tribunal de Leipzig estavam presentes um Prêmio Nobel (1909), Ostwald, e três futuros Prêmios Nobel: Haber (1918), Nernst (1920) e Bosch (1931) ${ }^{1}$.

Em quatro anos a BASF conseguiu transformar o aparelho de bancada de Haber-Le Rossignol, que produzia cerca de $100 \mathrm{~g}$ de $\mathrm{NH}_{3}$ por h, em um convertedor de $8 \mathrm{~m}$, na fábrica de Oppau (próximo a Ludwigshafen), produzindo $200 \mathrm{~kg}$ por h; uma ampliação de escala de 2.000 vezes ${ }^{1}$.

Os primeiros reatores construídos pela BASF, de 2,5 m de comprimento e $15 \mathrm{~cm}$ de diametro interno, em aço carbono, já foram um problema: operando a $100 \mathrm{~atm}(10 \mathrm{MPa})$ e $\sim 500{ }^{\circ} \mathrm{C}(\sim 773 \mathrm{~K})$ fragmentavam-se após $8 \mathrm{~h}$ de operação. O próprio Bosch, por meio da análise metalográfica, descobriu a causa: o hidrogênio, nestas condições, difundia-se pelo metal, reagia com o carbono do aço produzindo metano, rompendo o retículo cristalino (não havia na época aço inoxidável). Ele também encontrou a solução: fez o reator em tubos concêntricos (como os canhões). O tubo interno em ferro doce (sem carbono), com menos resistência mecânica porém imune ao hidrogênio, o segundo, envolvendo o interno, de aço carbono com pequenos furos, permitindo a difusão do hidrogênio e dando a resistência mecânica necessária para suportar a pressão $0^{1,11,12}$.

$\mathrm{Na}$ época não havia nada na indústria que se assemelhasse a este processo, com uma pressão tão alta. Muitos equipamentos, como compressores, bombas, válvulas, gaxetas, conexões, manômetros etc. tiveram que ser inventados, projetados e produzidos.

As matérias-primas para o processo (hidrogênio e nitrogênio) tiveram também de serem produzidas em quantidade e pureza elevadas. O hidrogênio era produzido a partir do coque, vapor d'água e ar, conforme indicado pela equações:

$\mathrm{C}(\mathrm{s})+\mathrm{H}_{2} \mathrm{O}(\mathrm{g})=\mathrm{CO}(\mathrm{g})+\mathrm{H}_{2}(\mathrm{~g})$ (alta temperatura)

$\mathrm{CO}(\mathrm{g})+\mathrm{H}_{2} \mathrm{O}(\mathrm{g})=\mathrm{CO}_{2}(\mathrm{~g})+\mathrm{H}_{2}(\mathrm{~g})$ (catalisador e alta temperatura)

$\mathrm{O} \mathrm{CO}_{2}$ é absorvido pela água, sendo aproveitado em outros processos. Inicialmente $\mathrm{o} \mathrm{N}_{2}(\mathrm{~g})$ era proveniente da liquefação do ar, depois utilizou-se a reação:

$2 \mathrm{C}(\mathrm{s})+\mathrm{O}_{2}(\mathrm{~g}, \mathrm{ar})=2 \mathrm{CO}(\mathrm{g})\left(>1000{ }^{\circ} \mathrm{C}\right)$

obtendo-se um gás com, principalmente, $62 \%$ de $\mathrm{N}_{2}$ e $32 \%$ de $\mathrm{CO}$, que, combinado com o processo de produção de hidrogênio, gerava a mistura inicial para síntese da amônia: $25 \%$ de $\mathrm{N}_{2}$ e $75 \%$ de $\mathrm{H}_{2}$. Havia ainda a necessidade de eliminar impurezas que envenenavam o catalisador: $\mathrm{H}_{2} \mathrm{~S}, \mathrm{O}_{2}$ e $\mathrm{CO}^{1,11}$.

Encontrar um catalisador barato e adequado foi a tarefa de Alwin Mittasch e seus colaboradores. Além do ósmio e urânio, utilizador por Haber e Le Rossignol, o ferro já havia sido utilizado anteriormente e os esforços dirigiram-se nesta direção. Foi montado na BASF um laboratório para desenvolvimento de catalisadores, com aparelhos semelhantes aos de bancada utilizados por Haber em Karlsruhe, para testar cerca de $2 \mathrm{~g}$ de amostra. Era uma tarefa que exigia um trabalho sistemático e repetitivo. Em novembro de 1909, encontraram uma boa amostra, partindo de uma magnetita $\left(\mathrm{Fe}_{3} \mathrm{O}_{4}\right)$ sueca. Além do ferro, o mineral continha impurezas de alumínio e sódio. A partir daí foram sintetizando diferentes amostras com diferentes promotores, até que chegaram a um catalisador com $\mathrm{Fe}, \mathrm{Al}_{2} \mathrm{O}_{3}, \mathrm{~K}_{2} \mathrm{O}, \mathrm{CaO}$ e $\mathrm{MgO}$. Note que o catalisador era produzido in situ, pois os óxidos de vários metais (como o ferro) são reduzidos por hidrogênio nesta temperatura. Até o início de 1912, o laboratório de Mittasch havia feito 6.500 testes com 2.500 diferentes amostras. Este trabalho prolongou-se até 1922, quando chegaram a mais de 20.000 testes e 4.000 diferentes amostras ${ }^{1,11,12}$.

A amônia produzida era utilizada em dois caminhos diferentes: reagindo diretamente com ácido sulfúrico, produzindo sulfato de amônio, para ser usado como fertilizante, ou oxidada a NO com o ar em presença de platina, depois, convertendo-se com ar e água, o NO a ácido nítrico ${ }^{1,11}$.

A façanha de se partir de um aparelho de bancada até uma fábrica, desenvolvendo um processo inteiramente novo em 4 anos, é, até hoje, notável.

Em 1922 a BASF inicia a produção industrial de uréia, a partir de amônia e gás carbônico, em um processo próprio ${ }^{1}$.

O processo indústrial da BASF para a amônia foi aos poucos sendo adotado por outros países, na década de 1920 em diante. Talvez as principais modificações foram na produção de hidrogênio, em que o carvão (coque) foi substituido por gás natural ou nafta, do petróleo, além de aperfeiçoamentos no processo, de purificação. Nas décadas de 1950-60, a empresa norte-americana M. W. Kellog fez uma reengenharia do processo, procurando torná-lo energetica- 
mente mais econômico: substituem-se os compressores a pistão por compressores centrífugos, com menos pressão, porém mais volume, catalisadores com diferentes compactações, que produziam menor queda de pressão no reator, novos trocadores de calor etc. Atualmente o processo industrial de síntese da amônia tem um custo energético, por $\mathrm{kg}$ de $\mathrm{NH}_{3}$ de $26 \mathrm{MJ}$, enquanto que o valor estequiométrico (valor ideal) é de $20,9 \mathrm{MJ}^{1}$.

\section{ALGUNS DADOS BIOGRÁFICOS}

Em toda esta história da síntese da amônia, sem dúvida nehuma, os principais atores foram Haber e Bosch. Alguns foram esquecidos, como Le Rossignol e Mittasch, o que é até compreensível pela dramaticidade da vida do primeiro. Vamos ver alguns aspectos das vidas de Haber e Bosch e súmulas biográficas de Mittasch e Le Rossignol.

\section{Fritz, Haber ${ }^{1,11-16}$}

Nasceu em 9/12/1868 em Breslau (Prússia), hoje Wroclaw (Polônia). De família judia, seu pai era um próspero comerciante de corantes, tintas, lacas, produtos químicos etc. Fritz não foi nenhuma criança prodígio. Casou-se em 1901 com Clara Immerwahr (1870-1915), sua conhecida de infância, com quem teve um filho. Clara foi a primeira mulher a doutorar-se (em Química) na Universidade de Breslau. Em 1917, Haber casa-se novamente com Charlotte Nathan, com quem teve um filho e duas filhas.

Após cursar o ginásio clássico em Breslau, Haber, com 18 anos, vai estudar Química na Universidade de Berlim, com August W. von Hoffmann (1818-1892), depois em Heidelberg, com Robert W. Bunsen (1811-1899) e em 1889 retorna a Berlim, matriculando-se na Universidade Técnica de Charlottenburg, estudando com Carl Liebermann (1824-1914), que também o orienta em seu doutorado (Química Orgânica), obtido em 1891. Após o serviço militar, passa por vários empregos na indústria, em diversas cidades, inclusive trabalhando com seu pai. Leciona como assistente em um período letivo no Instituto de Tecnologia de Zurich (Suíça) e acaba se decidindo por uma carreira acadêmica, assumindo posição de assistente (Química Orgânica) na Universidade de Jena. Nesta cidade se converte ao protestantismo, sendo batizado em 1892. Em 1894, vai para a Universidade Técnica de Karlsruhe, trabalhando com Hans Bunte (1848-1925). Nesta universidade passa a se dedicar à Físicoquímica, torna-se Privatdozent (1896) e Professor de Físico-química e Eletroquímica (1906).

Em 1898 publica o livro Fundamentos da Eletroquímica Técnica Sobre Uma Base Teórica e em 1905, Termodinâmica de Reações Gasosas Técnicas, um marco neste campo.

Vai para Berlim em 1911, assumindo a direção do Instituto de Físico-química e Eletroquímica da recém-criada Sociedade Kaiser Guilherme (hoje Sociedade Max Planck), uma cadeira na Universidade de Berlim e uma vaga na prestigiosa Academia de Ciências da Prússia.

Com o início da $1^{\text {a }}$ Guerra Mundial, Haber, com muitos outros cientistas, integra-se no esforço bélico alemão e torna-se depois Diretor do Serviço de Guerra Química, que deixa após o cessar das hostilidades.

Haber foi um notável cientista e diretor de pesquisas, trabalhando simultaneamente em diversos campos. Em seu tempo, o Instituto que dirigia em Berlim tornou-se a mais importante instituição no gênero no mundo. Não é possível alinhar os temas científicos em que Haber trabalhou, destacamos apenas alguns resultados dos mais conhecidos: o eletrodo de vidro para medir acidez de soluções, o ciclo de Haber-Born, mecanismos de reações, além da síntese da amônia. Um de seus colaboradores (S. Tamaru) afirmou que sua abordagem à pesquisa era penetrar nas raizes do problema com "minuciosidade e intolerância à imprecisão e superficialidade" ${ }^{11}$. Haber era também um excelente escritor e poeta nas horas vagas. $\mathrm{O}$ caso mencionado acima da construção do equipamento da síntese da amônia com Le Rossignol é também ilustrativo de sua personalidade.

Durante o conflito de 1914, Haber, assessorando o Exército Alemão, inicialmente cuidou das matérias-primas para a indústria voltada para a produção bélica, pois o Exército não contava com uma guerra longa e nem tinha se preparado para isto. Quem inicialmente começou a cuidar da chamada "guerra química" (utilização de gases irritantes ou venenosos como arma de guerra), também como assessor do Exército, foi Nernst, procurando substâncias que pudessem ser disseminadas, no campo inimigo, através de granadas. Entretanto, isso se mostrou pouco eficaz. Aí entra Haber, que planejou e comandou o primeiro ataque com gás cloro (Ypres, Bélgica, 22/4/1915). Em uma frente de cerca de $6 \mathrm{~km}$, milhares de cilindros contendo cloro foram abertos na direção das trincheiras francesas, assim que o vento se mostrou favorável. Seria, novamente, a velha rivalidade entre Nernst e Haber que motivou este último?

Alguns dias após o ataque de Ypres, Haber estava em Berlim e sua esposa Clara pediu-lhe que deixasse de trabalhar com gases venenosos; certamente ele não lhe deu ouvidos, e na madrugada de 2 de maio ela se suicida com a própria arma de Haber, então Capitão Honorário do Exercito Alemão. Dias depois ele embarca novamente para a linha de frente (agora na frente leste) e de lá escreve para um amigo: "Durante um mês, não pensava poder resistir a esse golpe, mas, na presença da guerra, acalmei-me, por força de ver as imagens sinistras e do dever de haurir os últimos recursos que existem em mim." Após o armistício Haber e Nernst foram procurados como criminosos de guerra, sendo que o primeiro fugiu para a Suíça (onde conseguiu se naturalizar), voltando para a Alemanha após os Aliados retirarem a acusação ${ }^{17}$.

$\mathrm{O}$ tratado de Versailles impunha à Alemanha uma pesada dívida de guerra. Haber preocupado com isto investiga o teor de ouro nas águas do mar, pois Svante Arrhenius (1859 - 1927) havia anteriormente publicado um valor de alguns miligramas de ouro por tonelada de água. Com um iate percorre o Atlântico e o Pacífico, no início da década de 1920, coletando amostras e analisando o ouro presente. Encontra um valor médio no Atlântico de 0,008 mg por tonelada, o que tornava inviável qualquer processo de extração.

Em 1918 é concedido a Haber o Prêmio Nobel de Química, apesar dos protestos dos Aliados, mas a cerimônia de entrega só ocorre em 1920.

Com a ascensão dos nazistas ao poder, em 1933, um dos primeiros decretos de Hitler foi excluir os "não-arianos" do serviço público, o que afetava Haber devido à sua origem judaica. Ele poderia continuar em suas funções devido a sua patriótica colaboração durante a guerra, entretanto demitiu-se, declarando: "Por mais de 40 anos selecionei meus colaboradores com base em sua inteligência e seu caráter e não com base em suas avós. Não pretendo mudar este método que sempre achei bom" ${ }^{14}$. Haber vai para a Inglaterra, mas logo desiste, devido ao clima úmido deste país (sua saúde declinava); resolve então aceitar um convite para ir trabalhar na Palestina, porém logo após morre na Suíça, onde pretendia repousar um breve tempo, em 19 de janeiro de 1934

O que se poderia chamar de "caráter dualístico" de Haber deveria ser objeto de maiores estudos e discussões. Muitas pessoas que com ele conviveram comentam seu temperamento afável c gentil ${ }^{13}$, outros, seu aspecto autoritário e tirânico ${ }^{17}$. De um ponto de vista ele pode ser considerado um benfeitor da Humanidade e, de outro, um malfeitor. Para alguns, ele era uma pessoa "normal", porém seu excessivo patriotismo levou-o a agir como um genocida. Uma análise psicológica profunda de Haber seria bastante valiosa a todos, principalmente pela implicações educacionais. 


\section{Carl Bosch $h^{1,16,19}$}

Carl Bosch nasceu em 27/8/1874, em Colônia (Alemanha). Seu pai era proprietário de uma empresa que vendia e instalava tubulações de água e gás. Carl cresce em meio a ferramentas e fazendo "experiências químicas", para desespero de sua mãe. Após terminar o ginásio clássico, seu pai o envia a Kotzenau, na Silésia, na fábrica metalúrgica de um amigo, onde o jovem Carl tem oportunidade de aprender diversos ofícios: modelagem, fundição, usinagem mecânica, carpintaria, claviculária etc. No ano seguinte, 1894, inicia seu estudos de Engenharia Mecânica e Metalúrgica na Universidade Técnica de Charlottenburg (Berlim). Após 2 anos vai para Leipzig, onde estuda Química e, em 1898, doutora-se (Química Orgânica) sob orientação de Johannes Wislicenus (1835-1902). Logo após seu doutoramento, envia currículo à BASF, relatando, além de sua vida acadêmica, todos os ofícios que aprendera e é imediatamente contratado para trabalhar na fábrica principal em Ludwigshafen. Suas primeiras tarefas foram sob a orientação de Rudolf Knietsch (1854-1906), na implantação da fabricação do índigo.

Bosch trabalhou em diversos projetos da BASF, inclusive sobre a fixação do nitrogênio (a partir de cianetos, nitretos, processo do arco elétrico, etc.), além do já mencionado caso da "síntese da amônia" com Ostwald (1900). Seu prestígio na empresa, junto a seus superiores, foi importante para a mesma decidir pelo processo de Haber, apesar das incertezas e riscos que o mesmo apresentava. A direção da BASF encarregou Bosch de gerenciar o projeto de implantação do mesmo. Da mesma forma a fábrica em Oppau e, depois, em 1917, a fábrica de Leuna.

Em 1919 Bosch passa para a Diretoria da BASF, participa de conferências diplomáticas representando a indústria alemã, por delegação do governo, inclusive nas negociações de paz de Versailles (1918/19). Em 1925, para contornar as dificuldades econômicas que a Alemanha enfrentava, suas principais empresas químicas (BASF, Bayer e Hoechst) e outras menores formam uma holding: Interessengememeinschaft der deutschen Farbenindustrie Atkiengesellschaft, ou simplesmente IG Farben, e Bosch torna-se seu Presidente. Após a vitória eleitoral do Partido Nazista, que assume o poder em 1933, Bosch tenta proteger os cientistas e empresários judeus e se recusa a ingressar no referido partido. Em 1937, Bosch deixa a presidência da IG Farben, indo para o Conselho e passa a dirigir a Sociedade Kaiser Guilherme (hoje Sociedade Max Planck).

Bosch, em 1931, juntamente com Friederich Bergius (1884-1949), recebe o Prêmio Nobel de Química, pelas contribuições à Química Industrial de altas pressões. Os últimos anos da vida de Bosch foram marcados pela depressão, que procurava contornar com analgésicos e álcool, causada inclusive pelo futuro desastroso que ele previa para a Alemanha. Em 20 de abril de 1940, muito doente, Bosch chama seu filho e lhe diz: "No começo tudo irá bem. ... Mas então ele trará a maior calamidade ao atacar a Rússia. Ainda tudo irá bem, por enquanto. Vejo, então, coisas terríveis. Tudo ficará totalmente negro. O céu está cheio de aviões. Eles irão destruir a Alemanha, suas cidades, suas fábricas e, também, a IG [Farben]"'. Falece no dia 26, antes que sua premonição se concretize. A Alemanha invade a Rússia (União Soviética) em 22 de junho de 1941.

Neste mesmo ano, a IG Farben reverte uma decisão anterior e resolve construir uma terceira fábrica de borracha sintética em Auschwitz, na Polônia, aproveitando, inclusive, a mão-de-obra dos prisioneiros. Estima-se que a IG Farben gastou 250 milhões de marcos, além de 200.000 vidas humanas em Auschwitz, e não produziu nem $1 \mathrm{~kg}$ de borracha ${ }^{1}$.

\section{Alwin Mittasch, 21-23}

Paul Alwin Mittasch (textos em língua inglesa às vezes grafam “Alvin”) nasceu em 27/12/1869 em Großdehs, Lobau (Alemanha) e faleceu em 4/6/1953 em Heidelberg (Alemanha). Estudou na Universidade de Leipzig ciências e humanidades, doutorando-se em Química, em 1901, sob orientação de Max Bodenstain (1871-1942) e Wihelm Ostwald. Começou a trabalhar na BASF em 1904, como assitente de Bosch. Em 1909 iniciou os estudos sobre catalisadores para síntese da amônia, onde fez toda sua carreira. Sobressaiu-se como químico de catálise e também como filósofo. Em 1951 veio a lume o texto por ele escrito em 1920: Geschichte der Ammoniaksynthese (Weinheim: Verlag Chemie), em que apresenta um relato pessoal da síntese da amônia, com destaque sobre o desenvolvimento dos catalisadores. Mittasch recebeu várias homenagens (honoris causa) de instituições alemãs. A Federação dos Engenheiros Químicos Alemães (DECHEMA), com patrocínio da BASF, instituiu em sua homenagem a medalha Alwin Mittasch para premiar trabalhos em catálise. Como filósofo, dedicou-se principalmente ao estudo da obra de Friedrich Nietzsche (1844-1900), além de aspectos filosóficos da Química. A ele se atribui a frase: "Química sem catálise é como uma espada sem controle, uma lâmpada que não ilumina ou um sino que não tine."

\section{Robert Le Rossignol, ${ }^{1,24}$}

Robert Le Rossignol nasceu em 1884 em St. Helier, Jersey, uma das Ilhas do Canal (Inglaterra) e faleceu em 1976 em Beaconsfield, Buckinghamshire (Inglaterra). Graduou-se em 1905 no University College (London), onde trabalhou com William Ramsay, indo logo depois para a Alemanha trabalhar com Haber. Logo de início Le Rossignol destacou-se por suas habilidades mecânicas, inventando uma válvula para controlar fluxo de gás, que foi patenteada e lhe rendeu bons proventos. Depois do trabalho com Haber continuou na Alemanha, trabalhando na companhia de lâmpadas elétricas Osram, como pesquisador. Quando iniciou a $1^{\text {a }}$ Guerra Mundial (agosto de 1914), foi feito prisioneiro, sendo libertado meses depois para continuar trabalhando na mesma empresa. Voltou para a Inglaterra em 1919, indo trabalhar na Osram inglesa, então associada da GEC. Passou logo depois para os laboratórios de pesquisas desta última, onde permaneceu até 1949, quando se aposentou. Na GEC trabalhou no desenvolvimento de válvulas eletrônicas de alta potência.

\section{EPÍLOGO}

A produção mundial de amônia em 2004 foi $117 \times 10^{9} \mathrm{~kg}^{20}$. Se toda essa amônia fosse disposta de uma vez em carretas de $20 \mathrm{t}$ e com $10 \mathrm{~m}$ de comprimento, dariam 1,46 voltas no equador terrestre. Cerca de $80 \%$ da produção mundial é utilizada como fertilizante, na forma de sais de amônio (nitrato, fosfato, sulfato), uréia etc ${ }^{1}$. Praticamente toda essa amônia é produzida por síntese e a proveniente da coqueficação da hulha é menos de $1 \%$ do total ${ }^{1}$. Os cinco países maiores produtores são, respectivamente, China, Índia, Rússia, Estados Unidos e Indonésia ${ }^{20}$.

Muito deste nitrogênio fixo, colocado como fertilizante, não é utilizado pelas plantas, é perdido para o meio ambiente ${ }^{1}$. Desnecessário dizer que há muito ainda para aprendermos em termos de agricultura. Toda a produção de amônia está atrelada à queima de combustíveis fósseis, uma vez que as principais matérias-primas, hoje utilizadas para produção de amônia, são gás natural e derivados do petróleo. Se no século XX a humanidade sobreviveu consumindo estas reservas, é ainda mais que necessário, neste século, procurar outros processos para a "fixação do nitrogênio". Como disse Crookes em 1898: "É o químico que deve vir salvar-nos..."

Que o leitor possa refletir sobre a importância deste processo industrial, a necessidade do nitrogênio e o cuidado com o ambiente, a vida e a obra dos personagens aqui citados e que tudo isto possa servir de lição e estímulo para todos nós. Não se pode esqueçer que a Ciência 
e a Técnica são atividades humanas e, no dizer de Pascal, "O coração tem razões que a própria razão desconhece"26.

\section{AGRADECIMENTOS}

Aos anônimos Assessores pelas correções e valiosas sugestões, inclusive pelo "caráter dualístico".

\section{REFERÊNCIAS}

1. Smil, V.; Enriching the Earth, MIT Press: Cambridge, Massachusets, 2000

2. Partington, J. R.; A Short History of Chemistry, $3^{\text {rd }}$ ed., Dover Publications: New York, 1989.

3. Brock, W. H.; The Norton History of Chemistry, W. N. Norton: New York, 1993.

4. Santos, K. M. O. dos; Dissertação de Mestrado, Universidade Estadual de Campinas, Brasil, 1989.

5. O'Neill, P.; Enviromental Chemistry, $2^{\text {nd }}$ ed., Chapman \& Hall: London, 1993

6. Silva, L. A.; Andrade, J. B.; Rosa, A. H.; Rocha, J. C.; Campos, M. L. A. M.; Jardim, W. F.; Martins, C. R.; Pereira, P. A. de P.; Lopes, W. A.; Cadernos Temáticos de Química Nova na Escola: Química, Vida e Ambiente, $\mathrm{n}^{\circ}$ 5, novembro de 2003

7. Chagas, A. P.; Termodinâmica Química, Ed. da Unicamp: Campinas, 1999.
8. Emsley, J.; The Elements, $3^{\text {rd }}$. ed., Clarendon Press: Oxford, 1998

9. Chase, M. W.; Davies, C. A.; Downey Jr., J. R.; Frurip, D. J.; McDonald, R. A.; Syverud, A. N.; JANAF Thermochemical Tables, $3^{\text {rd }}$ ed.; J. Phys. Chem. Ref. Data, 1985, 14, Supplement No. 1.

10. Simoni, J. de A.; Chagas, A. P.; Resumos da $28^{a}$ Reunião Anual da Sociedade Brasileira de Química, Poços de Caldas, Brasil, 2005

11. Tamaru, K. Em The History of the Development of Ammonia Synthesis in Catalytic Ammonia Synthesis: Fundamentals and Practice, Jenning, J. R., ed., Plenum Press: New York, 1991.

12. Berl, E.; J. Chem. Educ. 1937, 14, 203

13. Coates, J. E.; J. Chem Soc. 1939, 1642

14. Feldman, M. R.; Tarver, M. L.; J. Chem. Educ. 1983, 60, 463.

15. Travis, T.; Educ. Chem. 1994, 148.

16. http://www.nobelprize.org/chemistry, acessada em Novembro 2005.

17. Perutz, M. F.; La Recherche, ${ }^{\circ}$ 297, avril 1997, 78.

18. http://www.indexmundi.com, acessada em Novembro de 2005.

19. http://www.museum.villa-bosch.de, acessada em Novembro 2005.

20. Partington, J. R.; Quimica General e Inorganica, Ed. Dossat: Madrid, 1950.

21. http://de.wikipedia.org/Alwin_Mittasch, acessada em Novembro 2005.

22. http://www.basf.com, acessada em Novembro 2005.

23. Schummer, J.; Endeavour 2003, 27, 37.

24. Chirnside, R. C.; Chem. Britain 1977, 13, 269.

25. Uma foto da réplica desde aparelho pode ser vista no site: http:// www.chemheritage.org/educacionalservices/chemach/Theory and Production of gases/Fritz Haber, acessada em Fevereiro de 2006.

26. Ex memoria citatur. 